\title{
LXI Technologies for Remote Labs: An Extension of the VISIR Project
}

\author{
$\underline{\text { doi:10.3991/ijoe.v6s1.1385 }}$ \\ J. García-Zubía, U. Hernández-Jayo, I. Angulo,D. López-de-Ipiña, P. Orduña, J. Irurzun, O. Dziabenko \\ University of Deusto, Bilbao, Spain
}

\begin{abstract}
Several remote labs to support analog circuits are presented in this work. They are analyzed from the software and the hardware point of view. VISIR remote lab is one of these labs. After this analysis, a new VISIR remote lab approach is presented. This extension of the VISIR project is based on LXI technologies with the aim of becoming it in a remote lab easily interchangeable with other instruments. The addition of new components and experiments is also easier and cheaper.
\end{abstract}

Index Terms-analog electronics circuits, IVI, LXI, VISIR remote lab.

\section{INTRODUCTION}

In the practices of a first course in analog electronics, the students have their first contact with resistors and capacitors, as well as laboratory instrumentation. They learn to make the first resistance circuits to discuss their different combinations (series, parallel) or to see how a voltage divider works. They also make their first practical exercises with diodes working as rectifier and analyze a bit more complex circuits such as filters or voltage limiters based on Zener diodes.

But for these practices is also necessary to use lab equipment: oscilloscope, signal generator, multimeter and power supply. The matter is complicated: not only they must understand and run the circuit but also understanding and see how it works. If the warnings by the teacher on the use of equipment are added, work with tensions fear and that it is the first time that students are in a lab, it is normal to feel some trepidation before the laboratory practice.

In general, students need time to become familiar with equipment and overcome those fears to touch the buttons, spinning the roulette wheels and connecting cables. But unfortunately, time is missing, because every week there are new practices and it is always necessary to have assimilated the previous ones.

In addition, laboratories are often occupied by classes and many students who need extra time after hours to end the practices. In this scenario, a remote laboratory can help manage and resolve these problems, from home and using only an Internet connection.

For this reason, nowadays, several online remote labs are focuses on the development of experiments related with the analog electronics. The NetLab from the University of South Australia, [1], the RwmLAB from the Western Michigan University [2], the RemotElectLab from the School of Engineering, Polytechnic Institute of Porto [3], the ISILab from University of Genoa [4], the iLab from the Massachusetts Institute of Technology [5] and finally the VISIR developed by the Blekinge Institute of Technology [6].

All these laboratories have in common that are targeted for use in analog electronics subjects. Moreover, the users are allowed to built or reconfigure a real circuit (not virtual) using a web interface.

In the following sections, a brief analysis of each laboratory is going to be made, with a short explanation about how they work and the technologies used for their development. Then, the solution proposed by the University of Deusto is shown, stating the advantages of this solution over previous. Finally, the conclusions and future work are presented.

\section{NetLab. UnIVERSity OF SOUTH Australia.}

NetLab (http://netlab.unisa.edu.au/) is an online remote laboratory developed at the University of South Australia. NetLab is currently used by students and staff at the School of Electrical and Information Engineering for practicals and demonstration purposes. Being online, NetLab is available to students outside the scheduled practical hours but may also be used by registered visitors. NetLab provides remote access to real instruments and circuits and therefore presents users with real measurement data. NetLab is designed to give hands on experience through its realistic graphical user interface (GUI) which allows users to interact with instruments by pressing buttons and turning knobs like they would on real instruments. Using a circuit builder, the user has the chance of creating real experiments through a web site (Figure 1) [7].

\section{A. Software technologies}

NetLab is a Java based application, so it runs on any operating system provided it has an installation of Java SE

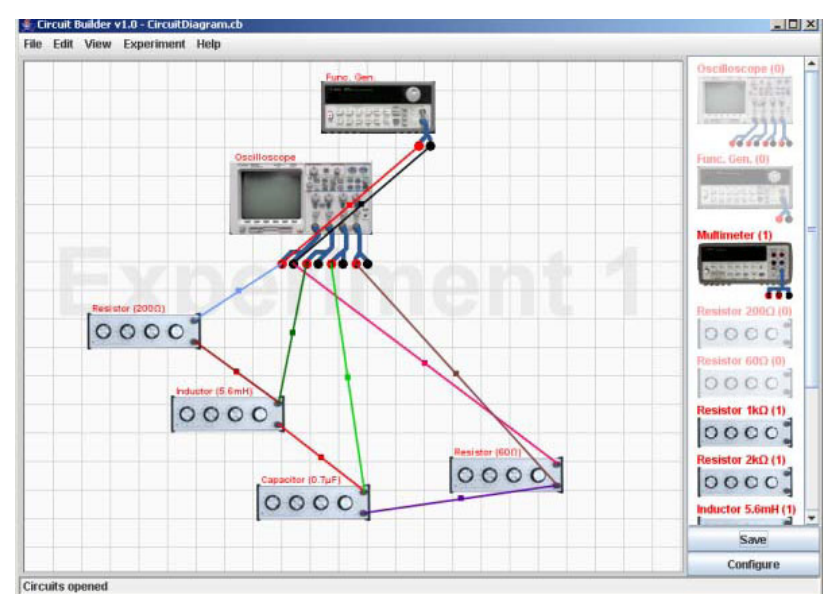

Figure 1. NetLab User interface 
runtime environment, version 6.0 or later. To run the NetLab application, students only need to download and setup an applet. Then, a shortcut is created in the desktop [8].

The actual instrument I/O uses National Instrument's VISA I/O library, through its $\mathrm{C}$ programming interface. This is exposed to Java through a created library called JVISA. It exposes most of the VISA API as objectoriented Java interfaces. This requires a very thin wrapper layer written in $\mathrm{C}$ which compiles the DLL.

The graphical interface is written in Java. All the instrument user interfaces are done using photographs of the instruments and done graphics using Java's 2D drawing capabilities.

\section{B. Hardware technologies}

The NetLab's circuit builder is based on a switching matrix with a $16 \times 16$ module available from Agilent (E1465A). This relay matrix switch requires supporting hardware that included: E8408A 4-slot VXI mainframe and the E1406A command Module. These components communicate with the NetLab server through the General Purpose Interface Bus (GPIB), while the VXI standard communication protocol is used for the internal communication within the Command Module (Figure 2).

The matrix module consists of 256 nodes formed by 16 rows and 16 columns. Nodes are switched thanks to double pole double throw (DPDT) latching relays. The structure of these latching relays allows having two separate layers, which each contain their own set of components [9]. Now, the students can use up to 16 two terminal components. This is limited by the number of matrix terminal which is $32 \max (16+16)$. Components like 4 channels will occupy 5 terminals.

The available instruments are a oscilloscope, a signal generator, a digital multimeter, four variable resistors, 2 variable capacitor, a variable inductor and one transformer.

\section{RWMLAB. WESTERN MICHIGAN UNIVERSITY}

The RwmLab has been developed by the Electrical and Computer Engineering Department of Western Michigan University. The goal of this remote lab is to address realtime remote wiring of electrical and electronic circuits, and real data acquisition using a Web-based application [10]. With this remote lab, students are able to wire up electrical and electronics circuits at the host laboratory using a Web Interface and by means of a conventional circuit board. The students also can connect instruments to the circuit and also change their settings. The data acquisition interface allows students to connect the instruments to all the nodes in the circuit and make measurements (Figure 3)

\section{A. Software technologies}

The web-based software used to develop the RwmLab has been written in HTML and JavaScript. When the user wires the circuit in the virtual breadboard, the software sends a digital code that represents the node/connections of the circuit. This code is sending using a common gate interface protocol (CGI), that it is written in $\mathrm{C}$ language.

The instruments controls and displays are been developed using National Instruments LabVIEW [11].

\section{B. Hardware technologies}

The Remote Wiring and Measurement Laboratory consist of a matrix switching board (Xecom's AWC86A) working as the controller of the platform with a Webbased server and a CPLD. The back-end of the matrix is an AMD 40-MHz AM186ES-based microcontroller with SRAM and Flash Memory (Figure 4).

The switching matrix is an $8 \times 8$ configurable array, based on solid-state relays and controlled by the Web microserver. The user can define the circuit using a "virtual breadboard'. Once the circuit is designed, the switching

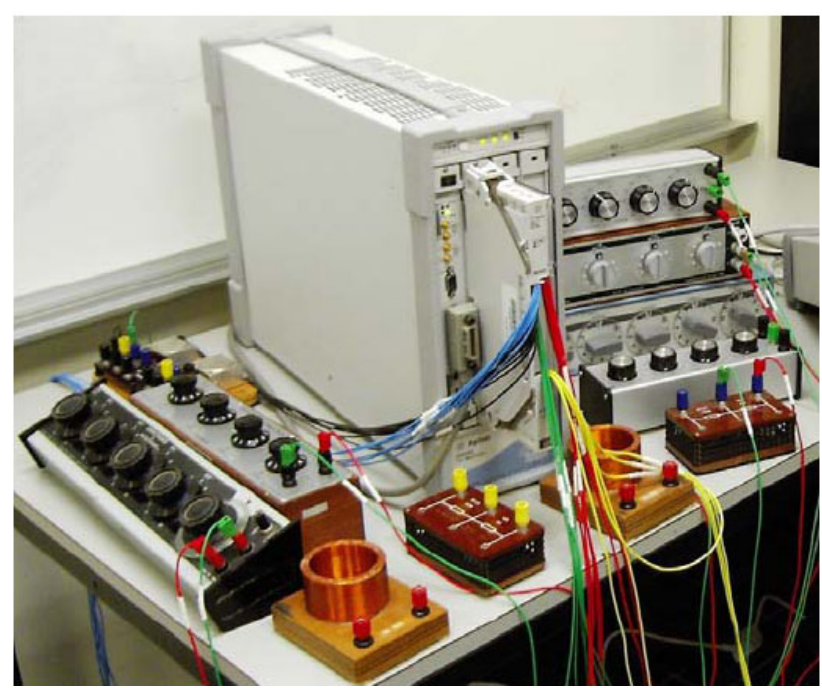

Figure 2. NetLab Switching matrix setup

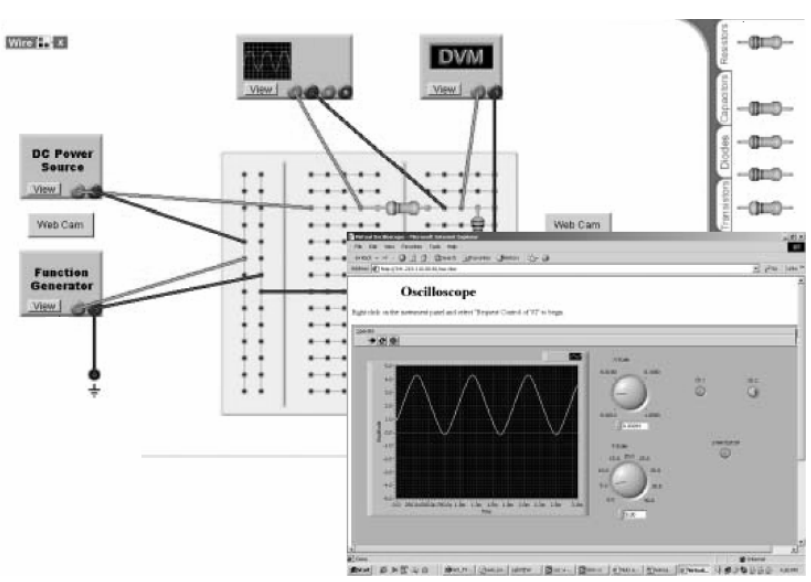

Figure 3. RwmLab User interface

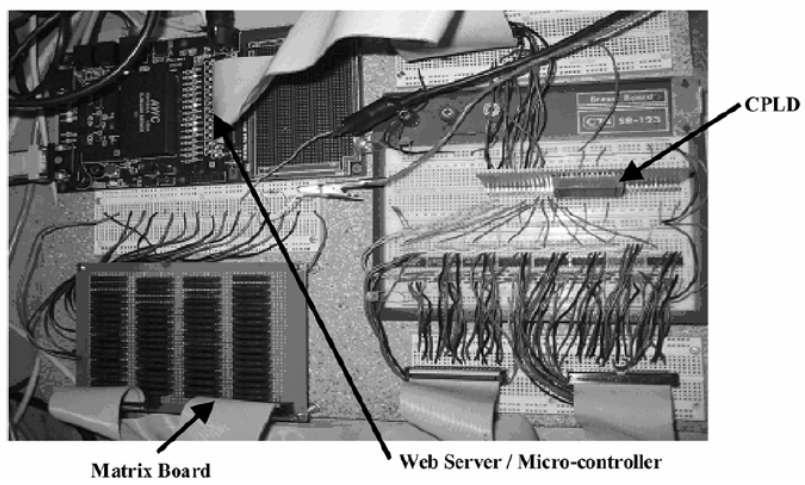

Figure 4. RwmLAB hardware platform 
matrix wires physically the electrical circuit in the laboratory. Components and wires placed around the "virtual breadboard" may be dragged by the user. The number of components is restricted by the number of connections available in the 8x8matrix [11].

A set of instruments are available. All of them have a GPIB interface and are fitted with a Webcam. The GPIB is used to control each instruments and to read the desired values in real-time. There are four instruments: digital multimeter, oscilloscope, power supply and waveform generator.

Once the user completes the circuit, it is analyzed by the software to determine which hardware must be connected together and to configure the relays.

\section{RemoteElectlab. Polytechnic Institute of PORTO.}

The remote lab for electronics teaching developed by the School of Engineering, Polytechnic Institute of Porto is currently being used as a complement in the course of Electronic II, 2nd year, and 1st semester of the Bachelor degree on Electrical \& Computer Engineering. During this course, the students study how the operational amplifier works, in which this remote lab is presented as one more learning tool. Using the user interface shows in the Figure 5, the students can modify part of the structure of the experiment and perform measures over it, analyzing the different values depending on the selected configuration.

\section{A. Software technologies}

All the software developed to deploy the RemotElectLab is based on LabVIEW from National Instruments. LabVIEW is a graphical language based on graphics. It is widely used in academia and industry mainly to instruments control. Additionally, other functions are defined, programmed and executed with other programming languages [12].

The GUI provided to the user is also based on LabVIEW (Figure 5), in which the student can change different parameters in the circuit under test.

One of the advantages of this approach is its easy integration in a Learning Manage System. In this case, all the functions related with the access management, information delivery, registering of results and evaluation can be provided by the LMS [3].

\section{B. Hardware technologies}

Hardware platform (Figure 6) is based on the National Instrument ELVIS (Educational Laboratory Virtual Instrumentation Suite) [21]. This platform can be used in a real lab and also to serve as a platform to build a remote lab. Besides the ELVIS, RemotElectLab includes a breadboard for the assemblage of the circuits, and a set of twelve integrated instruments (power supply, digital multimeter, oscilloscope and function generator), plus some analog and digital I/Os.

To allow the user to perform measures in different nodes on the circuit under test, switching modules working as multiplexers/demultiplexers were developed, based on electromechanical relays. With this solution, the user can also exchange components in a prefixed circuit and reconfigure it [3].

\section{ISILAB. UNIVERSITY OF GENOA}

The Internet shared Instrumentation Laboratory (ISILab) has been developed by the University of Genoa, and currently it is used to deliver remote access o experiments on electronics for the benefit of some engineering courses [13]. ISILab is a remote laboratory for practicing on electronic instruments and measurement methods executing real experiments of scalable complexity on analog and digital circuits. The experiments deal with basic electronic measurements, such as the delays in digital circuits or the gain and the distortion of amplifiers, and use a waveform generator and an oscilloscope. The laboratory integrates experiences, lectures, exercises, and hand-books that can be accessed through the user interfaces shown at Figure 7. This remote lab can be accessed at http://isilab.dibe.unige.it/.

\section{A. Software technologies}

ISILab has been designed using a distributed architecture in which the real laboratories can be spread over a wide geographic area and are accessed seamless by users. The web site portal shows the available experiments and

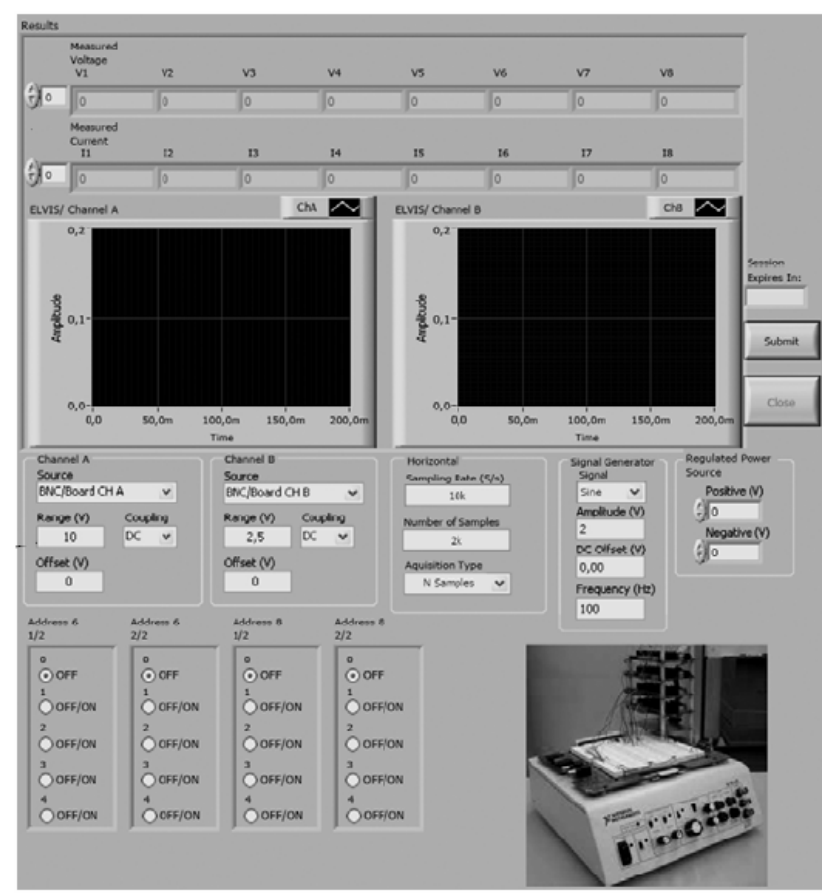

Figure 5. RemotElectLab User interface

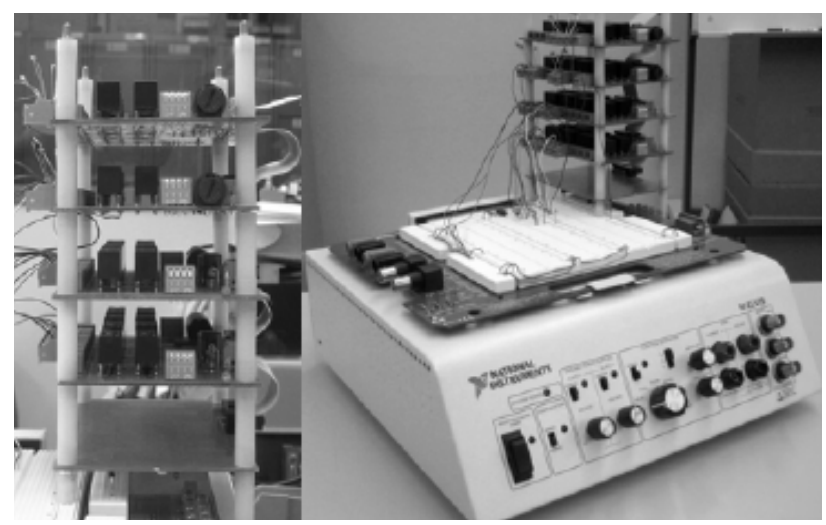

Figure 6. RemotElectLab hardware platform 


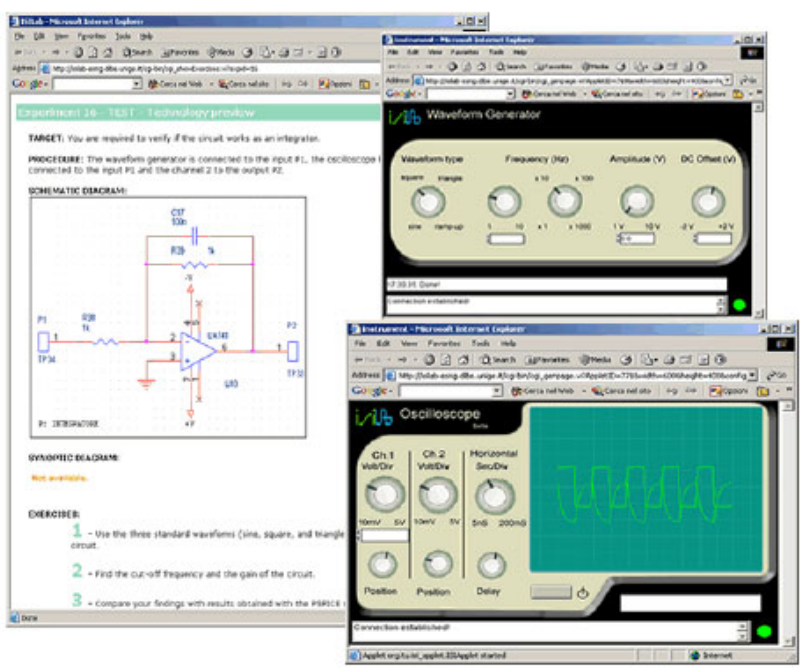

Figure 7. ISILab User interfaces

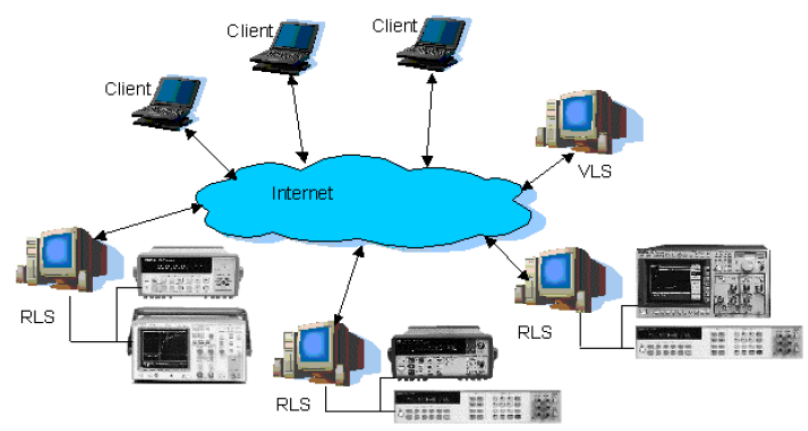

Figure 8. ISILab architecture

it is in charge of security policies and establishes the communication between the client and the Real Laboratory Server (RLS) in charge of the selected experiment (Figure 8).

To interact with the experiments, the user doesn't need any specific hardware or software except for a web browser and the Java Virtual Machine. Through the instrument virtual panels shown in web site, the user can control the instruments and interact with real experiments and instruments. These virtual panels are defined using a specific XML schema [14]. These GUI can be set up according to the objectives of each experiment and the users' skills. That is, ISILab has a general purpose and reconfigurable software modules that can be used to control different instruments. These modules can change their appearance and its behavior regarding with a configuration file.

This approach is based on the product called AppletVIEW shipped by Nacimiento [15]. This development environment let the developer build applet strongly integrated with programs written in LabVIEW. AppletVIEW configuration files are written using a XML-based language called VIML (Virtual Instrument Mark-up Language). ISILab has improves these method and the result is a Java applet that works on the base od these XML configuration files.

\section{B. Hardware technologies}

ISIlab supports both stand-alone instruments and computer-based ones (PCI, PXI, GPIB, etc.). It makes transparent the hardware using a homogeneous Application
Program Interface in the RLS engine. In this way, if a new instrument wants to be added, it only must be wrapped in an appropriate driver adapter to expose the device functionalities. These drivers' adapters are based on IVI (Interchangeable Virtual Instruments) technology [16] and they are developed for oscilloscope, function generator and digital multimeter.

If the students are offered to create circuit using discrete components, the number of components and relays to interconnect those increases exponentially with the number of components. For this and other reasons [17], ISIBoard has been created. It is a motherboard with sixteen slots, where the experiments' cards can be placed (Figure 9). Each card has eighteen lines for providing the power supply, output/input signals and for connections with the instruments. When the circuit is mounted on the motherboard, the connections with the instruments are dynamically created by a set of switches. That is, this motherboard works as a switching matrix controlled by the RLS, because each card has a unique identifier and a configurable array enables each circuit to share the same instrumentation. Depending on the experiment selected by the user in the web portal, the corresponding card in connected to the instruments and to the portal.

\section{ILAB. MASSACHUSETTS INSTITUTE OF TECHNOLOGY}

The iLab project (http://ilab.mit.edu) was started at MIT in 1998 by J. A. del Alamo [18][17], due to the frustration of not being able to teach practical subjects of semiconductor devices at MIT. Traditionally, students in these courses were exposed only to theoretical device models presented in lectures and course texts. An initial grant from Microsoft allowed Del Alamo explores the potential of remote access device. A first version was developed, called Microelectronics WebLab, based on a Java applet that allowed sending alerts to a server connected directly to the device using Microsoft ASP. In autumn 1998 the lab could be used by students, and by the spring of 1999 it had been used by nearly 100 students for practice.

In 2001, an architecture based on Web services began to develop. It provides a common infrastructure to all types of experiments, with development led by the Center for Educational Computing Initiatives at MIT. Moreover, this architecture stand for the first time-sharing experiments between different universities. In 2004, on this architecture called iLab Shared Architecture (ISA), a new version of the Microelectronics WebLab was developed as an experiment within the already called iLab.

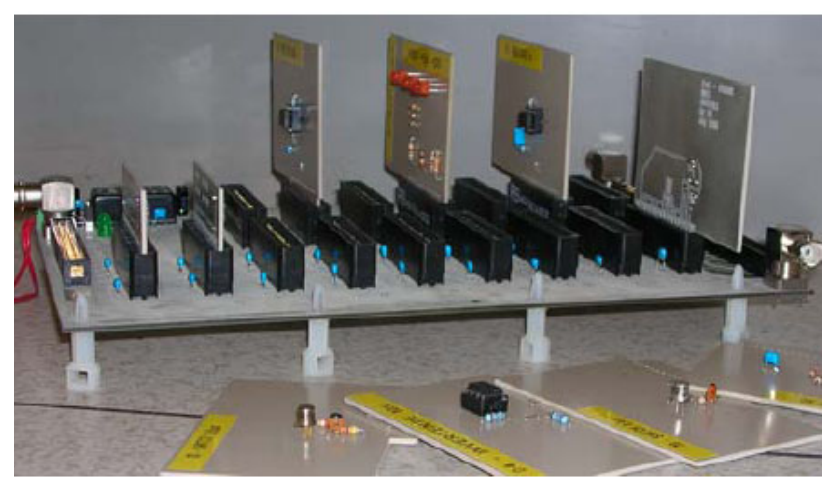

Figure 9. ISILab motherboard an experiments' cards 


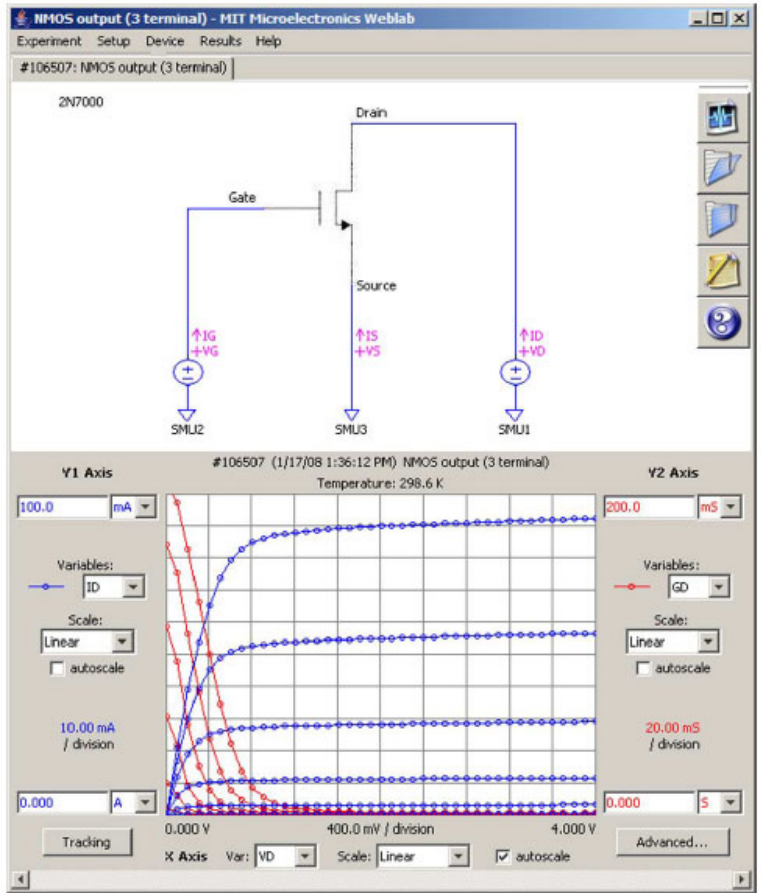

Figure 10. iLAB WebLab java Client

\section{A. Software technologies}

The iLab project is not domain specific. It attempts to provide a unifying context and middleware to support online laboratories from a wide variety of fields. Its main features are: a) It allows developing experiments on different platform and operating systems; b) Allows development of both interactive and batch experiments; c) Enables the sharing of experiments between different universities; d) Provide efficient management tools for laboratory providers; e) It has a scalable design.

iLab provides three categories of experiments: 1) Bached experiments, are those in which the entire course of the experiment can be specified before the experiment begins; 2) Interactive experiments are those in which the user monitors and controls one or more aspects of the experiment during its execution. 3) Sensor experiments are those in which users monitor or analyze real-time data streams [19].

Depending on the remote lab, iLab is developed using technologies that only works on Microsoft Windows. Although eventually you can develop an experiment over another platform by implementing the required interface, all servers are obligatory deployed under Microsoft Windows using privative technologies Microsoft IIS, Microsoft SQL Server and Microsoft Visual Studio for the development. Client is developed with multi-platform technologies like Java, so users of the system can use other platforms [20].

\section{B. Hardware technologies}

To control the semiconductor analyzer and the switching matrix used in the iLabs the server contain an Agilent GPIB interface board. Web services should also make it easier to incorporate vendor supplied modules in the overall architecture. The switching matrix allowed the system to host multiple semiconductor devices for characterization.

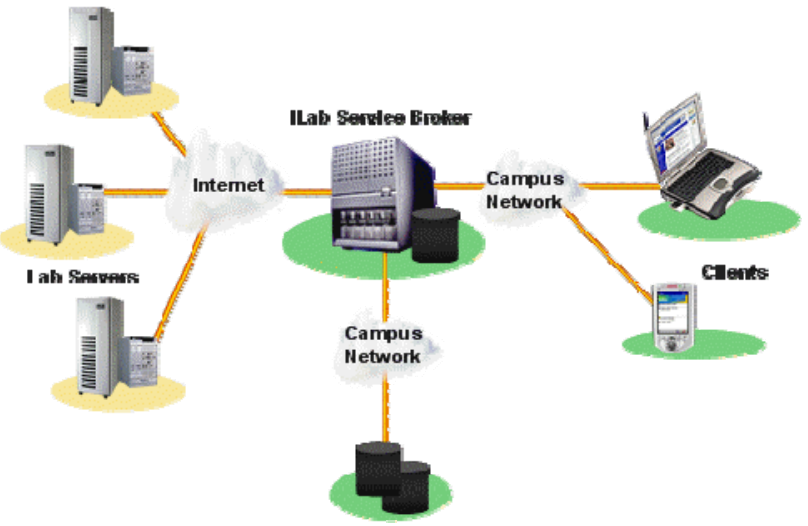

Figure 11. iLABs architecture

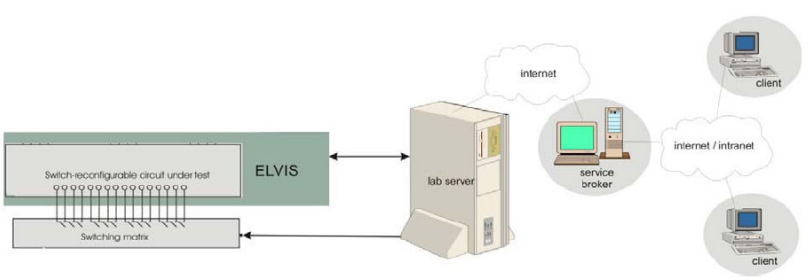

Figure 12. Architecture of iLab based on ELVIS platform

Recently, the iLab Project has focused on building remote laboratories around the National Instruments Educational Laboratory Virtual Instrumentation Suite (ELVIS) platform, an all-in-one electronics workbench. Different iLab based on ELVIS have been developed at MIT, using the hardware instruments available on ELVIS: the Function Generator, the Oscilloscope, DMM, Digital I/O, Bode Anaylzer, etc [21]. These instruments enable students to perform basic time domain measurements on electronic circuits and test and debug analog and digital circuits [22]. Using the combination of ELVIS and a switching matrix (Figure 12), the user can change the configuration of the system under test [23].

\section{VISIR. BLEKINGE InSTITUTE OF TECHNOLOGY}

The Signal Processing Department (ASB) at Blekinge Institute of Technology (BTH) has created an online lab workbench known as VISIR (Virtual Instrument Systems in Reality), for electrical experiments, mimicking and supplementing workbenches in local laboratories [24]. Using the VISIR interface, the students can create their own electrical circuit and test those using real components and real devices as oscilloscope, function generator, digital multimeter, and a power supply. The user interface (Figure 13) has been designed using the same front panels as the students use in the hands-on sessions, so they can reproduce the same actions and procedures as in the real laboratory.

\section{A. Software technologies}

The software architecture used to develop the VISIR lab is shown in Figure 14. This architecture is divided in different servers, each one plays a role in the laboratory set up and experimentation. VISIR is an OpenSource project, so all the software and related information can be download from http://svn.openlabs.bth.se [25][26].

- Web Server: The web server is in charge of being the join between the student at home and the experiment 
at the university. The user interface the student uses to create the circuit and test it has been developed in Adobe Flash, so the user only needs to install a Flash player to run the VISIR at his computer. However, the VISIR developer needs to run other applications to install the server located in the university. These other technologies are: a HTTP server, PHP 5 or later, Smarty, Text_Wiki and MySQL.

- Measurement Server: The main responsibility of the measurement server is to serve measurement requests, sent by the experiment clients. These requests are encoded using the experiment protocol, which contains the settings and functions of the equipment used in the experiment. The requests are then validated and transformed to a format that the equipment servers or directly connected instruments can understand. Authentication and queuing are also handled. The measurement server is written for Microsoft Windows, in $\mathrm{C}++$ using Microsoft Visual $\mathrm{C}++$, so it depends on their runtime libraries.

- Equipment Server: this server is in charge of receiving the measurement server requests and configures the instruments and the switching matrix, according with these requests. The interface between the measurement server and the equipment server is TCP/IP, so they can be running in separate machines. Equipment server is written in National Instruments LabVIEW and the instrument drivers are IVI [16] compliant, but there are not IVI drivers.

\section{B. Hardware technologies}

VISIR remote lab uses a National Instruments PXI chassis or a PCI solution to gather all the instruments needed to configure and perform measures over the real circuit built by the remote students. The available instruments are: oscilloscope, function generator, digital multimeter and power supply. All these instruments should be from National Instruments, because the LabVIEW Equipment Server is written using the drivers provided by National Instruments. If different manufacturer would be used, the code should be adapted.

To built the real circuit designed by the user using the web interface, VISIR uses a proprietary switching matrix (Figure 15) also controlled by the Equipment server. The relays are arranged in a three dimensional matrix pattern together with instrument connectors and component sockets. That is, there are two different card designs: one for instruments and one for components. In this way, the relay switches are embedded into the circuit created limiting the length of the wires in order to gain bandwidth. The nodes of the switching matrix are propagated from board to board creating a node bus. The notation "node" refers to the fact that every conductor created by these stacked connectors can be a node in a desired circuit [27].

\section{THE VISIR-LXI CONCEPT. UNIVERSITY OF DEUSTO}

Since 2008, the University of Deusto is enrolled in the VISIR consortium, which aim is to spread the VISIR project in those interested universities around the world. Carinthia University of Applied Sciences and FH Campus Wien University of Applied Sciences both in Austria are already involved in the VISIR project.
The University of Deusto started to work in 2001 in the development of remote labs, and the result of these works is the WebLab-Deusto [28]. One the main characteristic of the WebLab-Deusto (accessible at www.weblab.deusto.es) is its software architecture that has been developed completely independent of the experiment, hardware or instruments used in the remote lab [29].

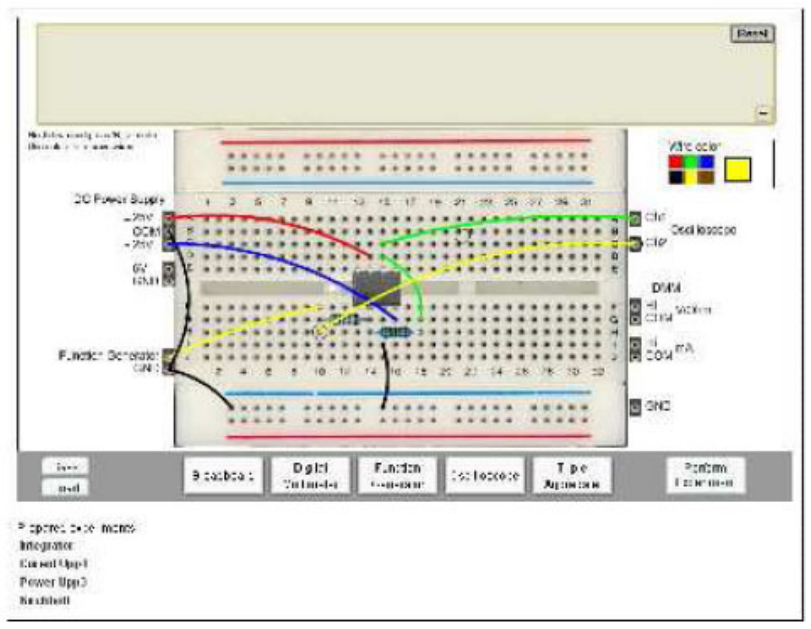

Figure 13. Virtual breadboard using in VISIR remote lab.

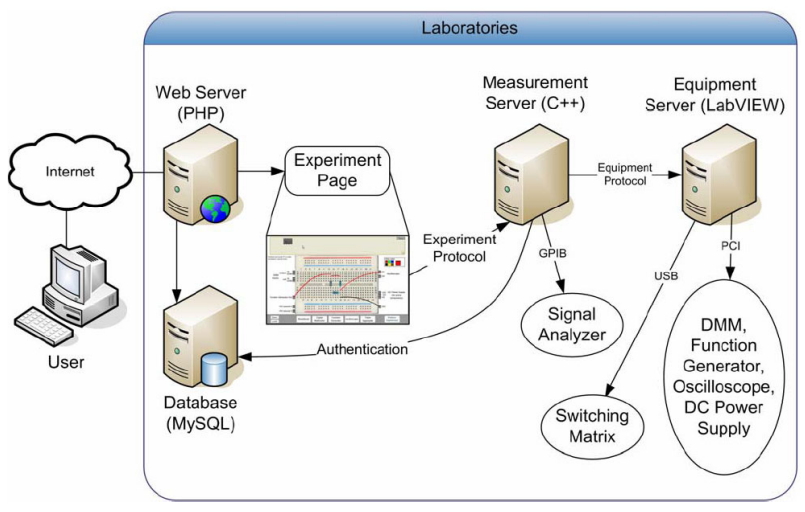

Figure 14. VISIR architecture

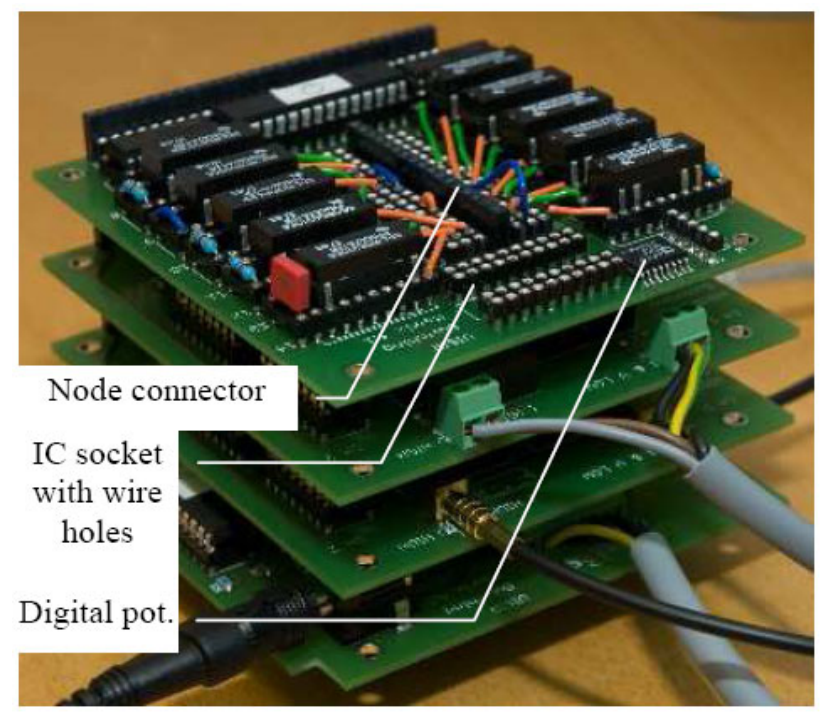

Figure 15. VISIR Switching Matrix 
Gathering the VISIR Project and the experience in the development of an unique software architecture in the WebLab-Deusto, the idea of creating a remote lab based on the potentials of the VISIR (its graphical interface and logic to control the experiment) and the advantages of WebLab-Deusto was born in 2009.

At the end of 2009, the version 3.9 of WebLab-Deusto has been released and now it is available at www.weblab.deusto.es. During that year, the hardware architecture of this VISIR-LXI started to be developed, based on the previous experience of the WebLab-GPIB [30] and a first experiment based on LXI instruments [31]. In this first work, the possibilities of LXI were analyzed and a simple laboratory based on this technology was presented.

\section{A. VISIR-LXI Objetives}

This remote lab is based on the VISIR concept and on the architecture shown at Figure 14, but some modifications have been applied, to achieve the following objectives:

- Create a remote lab independent of the instruments manufacturer.

- Use standards devices, not proprietary solutions.

- The instruments' configuration and control must be using standards and easily setup.

- Build a remote lab easily scalable and reconfigurable.

- It should be accessible by several students at the same time.

- Use a switching matrix configuration able to reduce the components needed to create complex circuits.

- This switch matrix should be able to be used with discrete components and/or prefixed circuits.

- Reduce the time a complexity of adding new experiments to the matrix

- The remote lab obtained should be able to be easily integrated into a Learning manage System.

- The obtained systems should be able to be wrapped into WebLab-Deusto platform.

- The cost of deploying this remote lab for electronics must be reduced.

\section{B. Software Technologies}

As it was described at section VII, the VISIR remote lab is divided into three different servers. These servers have been modified in the next way to be compliant with the cited objectives:

- Web Server: basically, this server has not modified, because the user interface developed in the VISIR project is really good and not easily improved. Nevertheless in following steps, the web server develop will be wrapped in the WebLab-Deusto code. The objective of this work is to be able to obtain more information about the actions that the user perform over the laboratory, because at present, the teacher only can know if a student has connected and when to the system, but there in not any else feedback about the performed experiment.

- Measurement Server: a new module called lxicom has been developed. The function of this module is to check the circuit created by the user in the bread- board and translate this circuit to a code that can be understood by the new circuit builder developed in the Equipment Server. This code contains the description of the wired circuit and the instruments connections on the circuit.

- Equipment Server: the instruments used in this lab are LXI compliant (only LXI-c is required) [32]. One of the characteristics of this standard is that the instruments must be IVI compliant to. In this way, the instruments controls have been rewritten completely using IVI drivers IVI. The main characteristic of these drivers is that they are completely independent of the manufacturer. That is, e.g. a scope IVI driver can be used to control a scope from any manufacturer that implements IVI drivers over their devices [16]. The circuit builder has also been rewritten completely due to in this lab, the switching matrix is a commercial solution, and it is not proprietary as at VISIR. Moreover, as the instruments are LXI compliant, the connection between the server and the instruments is through a standard Ethernet connection, and IP addresses are used to identify each instrument.

To configure the instruments, first, the instrument IVI driver must be installed and the IVISharedComponent must be setup. They can download from [16]. When this package is setup, the file IVIConfigurationStore.xml is saved. This file contents all the updates and registers about the IVI drivers that are setup in the system. This XML file configures the relationship between the IVI driver of each instrument and its $\mathrm{I} / \mathrm{O}$ reference. It also saves information regarding with the instruments' models and drivers so that just modifying the reference to the model, the instrument can be controlled without updating the code. The structure of the IVIConfigStore is shown at Figure 16.

\section{Hardware Technologies}

As it has been described before, the instruments are independent of the manufacturer. In our case, instruments from Agilent have been chosen N5746A (Power supply), DSO5012A (oscilloscope), 33220A (signal generator), 34410A (digital multimeter), 34980A (switching matrix), 2 x 34982A (matrix). (Figure 17).

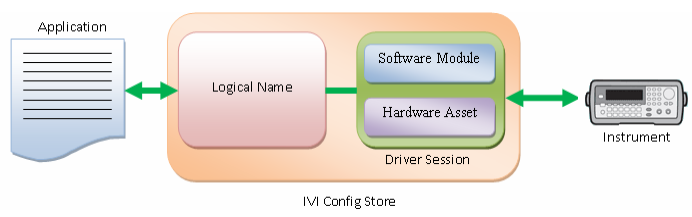

Figure 16. IVIConfig Store configuration

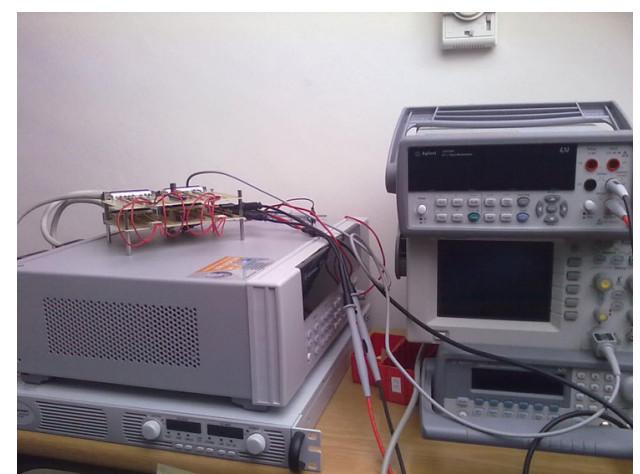

Figure 17. Instruments used at VISIR-LXI 
As all of them are LXI instruments, they are connected with the PC in which the equipment server runs, with a common Ethernet connection trough a Hub. In this case, the instruments form a subnet that can is acceded through the server (Figure 18). The server has a public IP but the instruments don't need it.

In this system, the proprietary switching matrix of the VISIR has been replaced by a commercial one. The selected switch is the $34480 \mathrm{~A}$ equipped with two dual $4 \times 16$ matrixes 34932A. These matrixes have been connected as is shown in Figure 19. The objective is to be able of creating the same circuits as in the VISIR platform, using less components and obtaining the same results.

In this moment we only are using the Slot 1 and Slot 5 . The switch has 8 slots, so it can host 8 dual 4x16 matrixes, because in each slot two matrixes $4 \times 16$ are setup. In each slot, the matrixes columns are interconnected (blue lines), and the matrix of different slots are joined by the rows (red lines). In example, if a new slot is occupied, its two matrixes will be interconnected (blue lines) and connected with matrix in Slot 1 and 5 through the rows (red lines). To create these interconnections, the boards shown in Figure 20 have been created.

The instruments are connected as follow:

- Function generator: Matrix 1 Slot 1 C16

- Oscilloscope channel2: Matrix 1 Slot 1 C15

- Oscilloscope channel1: Matrix 1 Slot 1 C14

- DMM HI: Matrix 1 Slot 1 C13

- DMM LO: Matrix 1 Slot 1 C12

- DMM I: Matrix 1 Slot $1 \mathrm{C} 11$

- Power supply +DC: Matrix 1 Slot 1 C10

Power supply Ground: Matrix 1 Slot 1 C9

The other columns are occupied by the discrete components. Each component is connected between two columns, so in each matrix 8 duel-terminal components can be connected.

The Equipment Server's Circuit Builder code is in charge of determinate which relays must be closed to wire the described circuit in the breadboard. Each node is determinate by two strings, one for the column and one for the row. In example, if a $10 \mathrm{~K} \Omega$ resistor is between $\mathrm{C} 1$ and $\mathrm{C} 2$ on Slot1 and is wanted to be connected in serial with a $1 \mathrm{~K} \Omega$ placed between $\mathrm{C} 16$ and $\mathrm{C} 15$ on Slot5, and then measure the equivalent resistance, the following strings must be sent to the switch matrix:

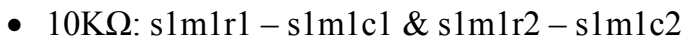

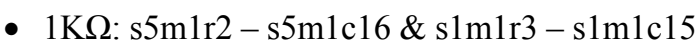

- DMM: s1m1r1-s1m1c13 \& s1m1r3-s1m1c12

The nodes of the components are represented at with red dots, and the nodes to connect the DMM with blue dots. The Circuit Builder uses a Circuit.list file to obtain the information about where are placed the components. This file is written by the developer or the instructor of the course. This file is easier to describe than the VISIR, because in this solution, a resistor can be connected in multiple nodes (R1 to R8). However, in VISIR a resistor only can be placed between two nodes.

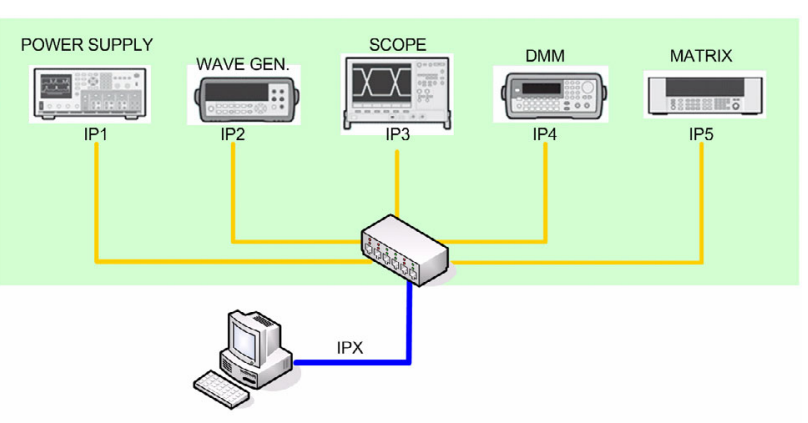

Figure 18. VISIR-LXI connections architecture

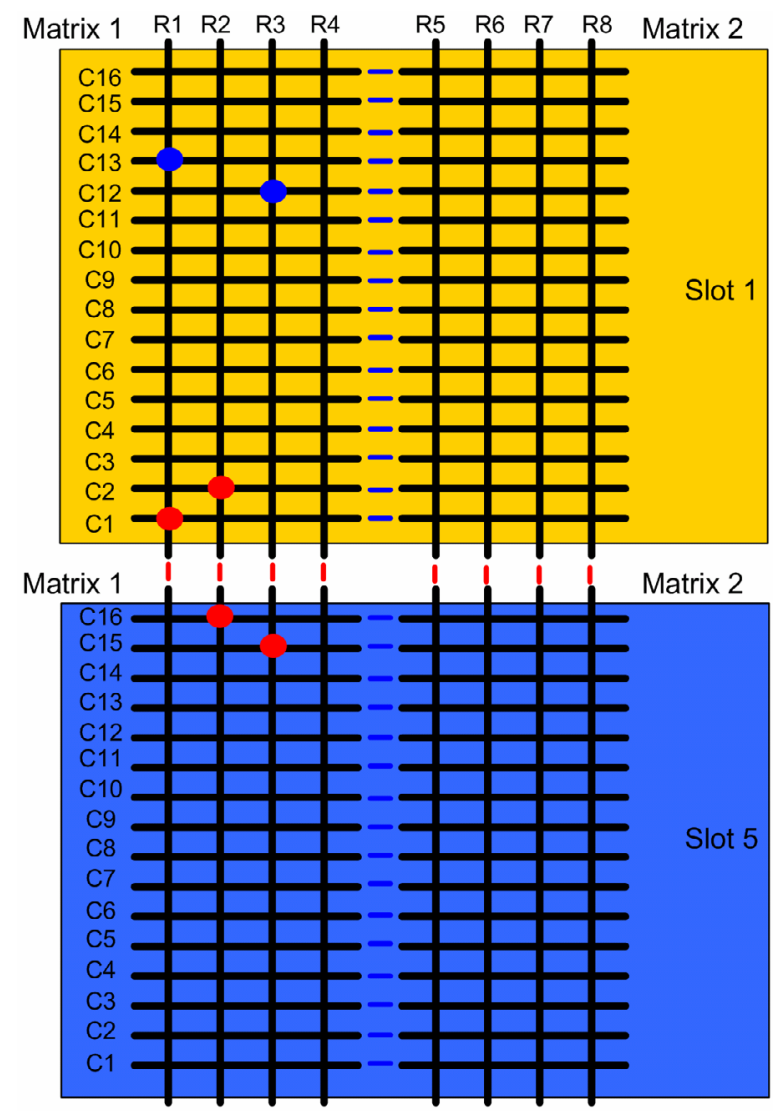

Figure 19. Switching matrix configuration

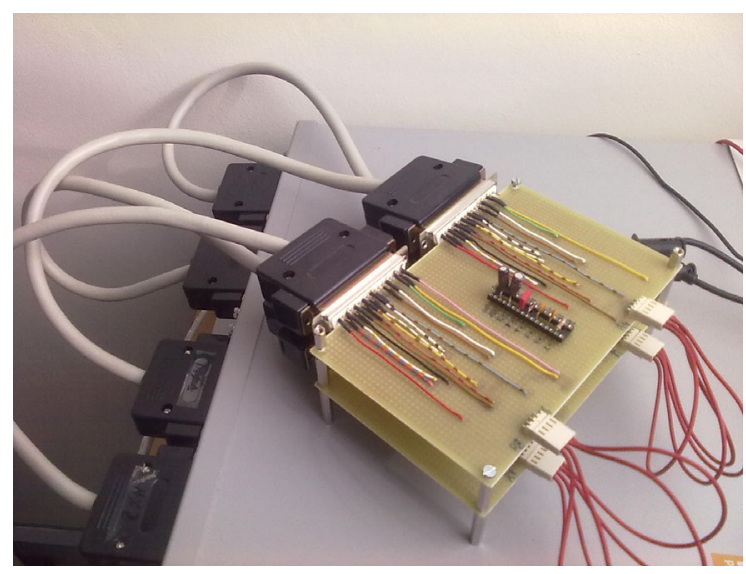

Figure 20. Connection board 


\section{Advantages and disavantages over the privious} solutions

The principal advantages and disadvantages of this beta system, respect the previously analyzed are:

Advantages:

- Using LXI-IVI compliant instruments, the developer can choose the solution best fits with his requirements.

- Using IVI drivers, the used instruments are transparent for the developer.

- The connection with the instruments is over a common Ethernet connection. Not special hardware (GPIB, PXI, VXI or others) is required.

- The price of the needed instruments is lower than the used in the VISIR. Cheaper solutions can be found in the market.

- Once the VISIR-LXI will be wrapped in WebLabDeusto, it should be easily integrated into a LMS.

- A component can be placed in multiple nodes. The number of components needed to created different circuits is reduced.

- The file that describes where are placed the components and the file that describes how the components can be wired by the user, are easier to write than in VISIR.

- The created boards to place the components and to interconnect the matrixes are very simple, so they are not expensive.

Disadvantages

- Although the solution will be open source when it will be finished, a LabVIEW distribution will be required to run the equipment server. Other solutions should be analyzed to over this inconvenient.

- By the moment, only circuits with single polarization can be used, because the chosen power supply has not implemented negative tension.

- The number of components is limited by the number of slots available in the switch. With the configuration shown here, 52 components (2-terminals) can be placed.

- The maximum signal frequency tested has been $30 \mathrm{MHz}$. Over this frequency, the signal can be distorted.

- It has not tested yet with students accessing at the same time to the platform. The relays time response could be a problem, and the number of user working at the same time could be reduced.

TABLE I.

COMPARISON BETWEEN PREVIOUS LABS

\begin{tabular}{|c|c|c|c|c|c|c|c|}
\hline & NetLab & RwmLAB & RemotElectLab & ISILab & iLab $^{(1)}$ & VISIR & VISIR-LXI \\
\hline Circuits & Discrete & Discrete & Fixed and modifiable & Fixed & Fixed & $\begin{array}{l}\text { Fixed, modifi- } \\
\text { able and dis- } \\
\text { crete }\end{array}$ & $\begin{array}{l}\text { Fixed, modifiable } \\
\text { and discrete }\end{array}$ \\
\hline $\begin{array}{l}\text { Instruments } \\
\text { control }\end{array}$ & GPIB-VXI & GPIB & NI-ELVIS & $\begin{array}{l}\text { PXI, PCI, GPIB } \\
\text { under IVI drivers }\end{array}$ & $\begin{array}{l}\text { GPIB, NI- } \\
\text { ELVIS, etc }\end{array}$ & PXI & $\begin{array}{l}\text { LXI and IVI } \\
\text { drivers }\end{array}$ \\
\hline $\begin{array}{l}\text { Control Soft- } \\
\text { ware }\end{array}$ & JAVA & LabVIEW & LabVIEW & LabVIEW & LabVIEW & LabVIEW & LabVIEW \\
\hline Matrix & Agilent E1465A & $\begin{array}{c}\text { Xecom } \\
\text { AWC86A + } \\
\text { owner matrix }\end{array}$ & $\begin{array}{l}\text { NI-ELVIS + Owner } \\
\text { switching modules }\end{array}$ & $\begin{array}{l}\text { Owner mother- } \\
\text { board matrix }\end{array}$ & NI-ELVIS & $\begin{array}{l}\text { Owner switch- } \\
\text { ing matrix }\end{array}$ & $\begin{array}{l}\text { Agilent 34980A } \\
\text { and 34982A }\end{array}$ \\
\hline Availability & Yes & No & Guest & Yes & Yes & Guest & Guest (Under test) \\
\hline Concurrency & $\begin{array}{l}\text { Three users at } \\
\text { the same time }\end{array}$ & $\begin{array}{l}\text { Without in- } \\
\text { formation }\end{array}$ & No & $\begin{array}{c}\text { Several users can } \\
\text { be watching the } \\
\text { experiment at same } \\
\text { time }\end{array}$ & No & $\begin{array}{l}\text { Max } 16, \text { de- } \\
\text { pending on the } \\
\text { experiment }\end{array}$ & Yes (Under test) \\
\hline $\begin{array}{l}\text { User Inter- } \\
\text { face }\end{array}$ & $\begin{array}{l}\text { Virtual Work- } \\
\text { bench in Java }\end{array}$ & $\begin{array}{l}\text { Virtual Bread- } \\
\text { board in Java }\end{array}$ & LabView front panel. & $\begin{array}{c}\text { AppletView and } \\
\text { AJAX }\end{array}$ & Java Applet & $\begin{array}{l}\text { Virtual bread- } \\
\text { board in Flash }\end{array}$ & $\begin{array}{l}\text { Virtual bread- } \\
\text { board in Flash }\end{array}$ \\
\hline $\begin{array}{l}\text { Singular } \\
\text { features }\end{array}$ & $\begin{array}{l}\text { It includes a } \\
\text { collaborative } \\
\text { platform for } \\
\text { students and } \\
\text { teachers. }\end{array}$ & $\begin{array}{l}\text { The matrix is } \\
\text { controlled by } \\
\text { a CPLD }\end{array}$ & $\begin{array}{l}\text { Easily deployable } \\
\text { using LabView re- } \\
\text { mote panels }\end{array}$ & $\begin{array}{l}\text { XML is used to } \\
\text { describe the whole } \\
\text { experiment }\end{array}$ & $\begin{array}{l}\text { Integrated } \\
\text { into ISA } \\
\text { architecture. }\end{array}$ & $\begin{array}{l}\text { Powerful user } \\
\text { interface }\end{array}$ & $\begin{array}{l}\text { Independent from } \\
\text { the manufacturer } \\
\text { using LXI. }\end{array}$ \\
\hline
\end{tabular}

\footnotetext{
${ }^{(1)}$ Experiment based on analog electronics with NI-ELVIS
} 


\section{COMPARISON BETWEEN REMOTE LABS FOCUS ON ANALOG ELECTRONICS CIRCUITS}

Table I shows the comparison between the remote labs analyzed previously. All of them are based on analog electronics circuits, although some of them are prepared to deploy digital circuits, as in ISILab. iLAB is an special case, because iLABS hosts several diverse thematic remote labs. To perform this comparison, the iLAB based on NI-ELVIS and analog circuits has been analyzed.

The comparison has been performed analyzing the following characteristics:

- Circuits: the user can build the complete circuit using discrete components: discrete. Fixed: the user only can change the inputs of the circuits and analyze the outputs. Modifiable: part of the circuit is fixed and the user can change some parts of it.

- Instruments control: the communication interface used to control the instruments.

- Control Software: the software technology used to control the instruments

- Matrix: the used matrix that gathers the different circuits available in the lab or the discrete components to build the circuits.

- Availability: is the remote lab open for all users? Do you need an account? Can you access as a guest?

- Concurrence: could the lab be used by several students at the same time?

- User interface: the technologies used to develop the user interface.

\section{CONCLUSIONS AND FUTURE WORK}

Some solutions to create remote labs to support practical lessons in analog electronics subject have been presented in this paper. All of them have been developed using proprietary solutions from the software and hardware point of view. These approaches make difficult to replace the instruments for other ones, or to create new experiments in an easy and fast way, because in all remote labs, the used technologies during the development, determinate the characteristics of the WebLab.

The VISIR-LXI solution presented here is the first step to develop a remote lab completely independent from the instruments and that enables the addition of new components and experiments easily.

This remote lab must to be tested with students in a current year to obtain results about its performance and compare it with the VISIR solution from the students and utilization point of view. It has been compared from the instructor side, and it has been proved that the addition of new components and the creation of wiring rules are easier than in VISIR. I has also tested, that to create different circuits using the same components (i.e. resistors configurations), less components are required than in VISIR.

In future steps, expected LXI oscilloscope will be added to the lab and then the remote VISIR-LXI will be completed. The software will be wrapped into the WebLab-Deusto software and the functions related with the administration and management will be supported by it. Applications to obtain information about the users' actions on the lab will be developed.
This remote lab is wanted to be included into a Learning Management System to analyze if it is possible to generate random questions for the students to be implemented over the remote lab and correct their results automatically using the LMS.

\section{REFERENCES}

[1] Machotka. J, Nedic, Z. Calabrese, R. and Chen, M.., 'The development of a remote laboratory (NetLab) the University of South Australia', Proceedings of the $7^{\text {th }}$ Baltic Region Seminar on Engineering Education, St Petersburg, Russia, 133 - 136 (2003).

[2] Asumadu, J., Tanner, R., Fitzmaurize, J., Kelly, M., Belter, J., Chin Koh, S., "A Web-Based Electrical and Electronics Remote Wiring and Measurement Laboratory (RwmLAB) Instrument", IEEE Transactions on Instrumentation and Measurement, Vol. 54, No. 1, February 2005. doi:10.1109/TIM.2004.834597

[3] Sousa, N., Gericota, M., Alves, G., 'Um Laboratório Remoto, Múltiplas Potencialidades'. II Jornada Luso-Brasileira de Ensino e Tecnologia em Engenharia - JLBE 2009

[4] Andrea Bagnasco et al., "A Configurable Remote Laboratory for the Flexible Setup of Experiments in Electronics", in: Advances on remote laboratories and e-learning experiences, pp. 271-284, Luís Gomes and Javier García-Zubía (eds.), University of Deusto, 2007, ISBN:978-84-9830-077-2

[5] Alamo del, J.A., Hardison, J., Mishuris, G., Brooks, L., McLean, C., Chan, V., and L. Hui. Educational experiments with an online microelectronics characterization laboratory. In Proceedings Int. Conf. Eng. Educ., August 2002.

[6] I. Gustavsson et al. (2007). 'The VISIR project - an Open Source Software Initiative for Distributed Online Laboratories', Proceedings of the REV 2007 Conference, Porto, Portugal, June 25 - 27, 2007.

[7] Nedic, N., Machotka, J. "Remote Laboratory NetLabfor Effective teaching of $1^{\text {st }}$ year engineering students”. Proceedings of the REV 2007 Conference, Porto, Portugal, June 25 - 27, 2007.

[8] Nedic, N., Machotka, J. "From the collaborative Environment of Remote Laboratories to the Global Collaboration”. Proceedings of the REV 2008 Conference, Dusseldorf, Germany, June 23 - 25, 2008.

[9] Nedic, N., Machotka, J., Sprok, A., Ruud, L. O., Carr, S. “The circuit builder for NetLab". $8^{\text {th }}$ UICEEAnnual Conference on Engineering Education. Kingston, Jamaica, 7-11 February 2005.

[10] Asumadu, J., Tanner, R., "Remote wiring and measurement lab". In Proc. American Society Eng. Educatin Annual Conf. Exposition, Albuquerque, NM. June 24-27, 2001

[11] J.A. Asumadu, R. Tanner, J. Fitzmaurice, M. Kelly, H. Ogunleye, J. Belter and Song Chin Koh, "A Web-Based Electrical and Electronics Remote Wiring and Measurement Laboratory (RwmLAB) Instrument," IEEE Trans. on Instrumentation and Measurement, vol. 54, no. 1, pp. 8-44, February 2005, doi:10.1109/TIM.2004. $\underline{834597}$.

[12] García-Zubia, J., Orduña, P., López de Ipiña, D., Alves. G. “Addressing Software Impact in the Design of Remote Labs.” IEEE Transactions on Industrial Electronics. ISSN: 0278-0046; Volume 56, Issue 12, Dec. 2009 Page(s):4757 - 4767.

[13] Bagnasco A., Chirico M., Parodi G., Scapolla A.M., "A Virtual Laboratory for Remote Electronic Engineering Education", in International Perspective on Tele-education and Tele-learning, Ashgate Book, 2000, pp. 1-14

[14] Bagnasco A., Chirico M., Scapolla A.M. " XML Technologies to Design Didactical Distributed Measurement Laboratories " IMTC 2002, IEEE Instrumentation and Measurement Technology Conference, Anchorage, Alaska, USA May 21-23, 2002.

[15] Nacimiento AppletVIEW, http://www.nacimiento.com

[16] IVI drivers, http://www.ivifoundation.org

[17] Bagnasco, A., Parodi, G., Ponta, D., Scapolla A. M., “A Modular and Extensible Remote Electronic Laboratory”. Vol. 1, No. 1 (2005) of International Journal of Online Engineering, ISSN: 1861-2121

[18] V.J. Harward, J.A. del Alamo, S.R. Lerman, P.H. Bailey, J. Carpenter,K. DeLong, C. Felknor, J. Hardison, B. Harrison, I. Jabbour, P.D.Long, Tingting Mao, L. Naamani, J. Northridge, M. 
Schulz, D. Talavera,C. Varadharajan, Shaomin Wang, K. Yehia, R. Zbib, and D Zych. "The iLab Shared Architecture: A Web Services Infrastructure to Build Communities of Internet Accessible Laboratories". Proceedings of the IEEE, Vol. 96, No. 6, 2008.

[19] Hardison, J. and DeLong, K. and Bailey, P. and Harward, V.J. "Deploying Interactive Remote Labs Using the iLab Shared Architecture”. In Frontiers in Education (FIE) Conference, October 2008

[20] del Alamo, J. A., L. Brooks, C. McLean, J. Hardison, G. Mishuris, V. Chang, and L. Hui, "MIT Microelectronics WebLab", chapter in T. Fjeldly and M. Shur, Eds., Lab on the Web - Running Real Electronics Experiments via the Internet, Wiley-IEEE, 2003, pp. 49-87.

[21] NI ELVIS Specifications, www.ni.com/pdf/manuals/372590a.pdf.

[22] Soumare, H., Shroff, R., Hardison, J.L., del Alamo, J. A.,Harward, V. J., Bailey, P. H. DeLong, K. K. "A Versatile Internet-Accessible Electronics Workbench with Troubleshooting Capabilities” Proceedings of the REV 2009. June 2009. Bridgeport, CT

[23] Ayodele, K., Akinwale, O., Kehinde, L., Osasona, O., Ajayi, E., Akinwunmi, O. "Advanced Digital Laboratory: An FPGA-Based Remote Laboratory for Teaching Digital Electronics." ASEE. June 14, 2009. Austin, TX.

[24] I. Gustavsson et al., "An Instructional Electronics Laboratory Opened for Remote Operation and Control", Proceedings of the ICEE 2006 Conference, San Juan, Puerto Rico, July 23 - 28, 2006.

[25] Gustavsson, I., Nilsson, K., Hernández-Jayo, U., Garbi, G., Alves, G. "How to open a local electronics laboratory for remote access". Proceedings of the ICBL 2008 Conference, November 03 05, 2008 Florianopolis, Brazil

[26] Zackrisson, J., Gustavsson, I., Håkansson, L. “An Overview of the VISIR Open Source Software Distribution 2007” Proceedings of the REV 2007 Conference, Porto, Portugal, June 25 - 27, 2007

[27] Gustavsson, I., Zackrisson, J., Ström Bartunek, J., Nilsson, K., Håkansson, L., Claesson, I., and Lagö, T. “Telemanipulator for Remote Wiring of Electrical Circuits”. Proceedings of the REV 2008 Conference, Dusseldorf, Germany, June 2008.

[28] Orduña, P., García-Zubia, J., Irurzun, J., Sancristobal, E., Martín, S.,Castro, M., López-de-Ipiña, D., Hernández-Jayo, U., Angulo, I., González, J.M. "Designing Experiment Agnostic Remote Laboratories”. Proceedings of the REV 2009. June 2009. Bridgeport, CT

[29] García-Zubia, J., Orduña, P., Angulo, I ., Irurzun, J., HernándezJayo, U. "Towards a distributed architecture for remote laboratories”. Proceedings of the REV 2008. June 2008. Dusseldorf, Germany.

[30] García-Zubia, J., López-de-Ipiña, D., Ponta, D., Hernández-Jayo, U., Orduña, P., Trueba, I. "WebLab-GPIB at University of Deusto". Proceedings of the REV 2007 Conference, Porto, Portugal, June 25 - 27, 2007.

[31] García-Zubia, J., Hernández-Jayo, U., Angulo, I., Orduña, P. “Remote laboratories based on LXI" ". Proceedings of the REV 2008 Conference, Dusseldorf, Germany, June 2008.

[32] LXI Standard. www.lxistandard.com

\section{AUTHORS}

J. García-Zubia is with University of Deusto, Electronics and Automation Department, Avenida de las Universidades 24, 48007 Bilbao (Spain), is with the University of Deusto, he is Head of Dpt. Of Industrial Electronics, Control Engineering, and Computers Architecture of the Faculty of Engineering. He is the responsible of the remote lab at the University of Deusto (WebLabDEUSTO: weblab.deusto.es). The WebLab-Deusto has been implemented using web 2.0 techniques (AJAX, SOAP, etc.), this approach is a novelty in Europe. Different works have been published explaining the results and the technology of this weblab and the evolution of WebLab-DEUSTO has been supported by different projects. (e-mail: zubia@eside.deusto.es).

U. Hernández is with the University of Deusto in the Telecommunications Department at the Faculty of Engineering. He is developer of the research group on webbased laboratories and he is in charge of the remote labs based on instruments control. He is involved too in the deployment in University of Deusto of the VISIR project leaded by the Blekinge Institute of Technology (Ronneby, Sweeden). (e-mail: unai.hernandez@deusto.es).

I. Angulo is with the University of Deusto in the Dpt. of Industrial Electronics, Control Engineering, and computers Architecture of the Faculty of Engineering. He is the lead hardware designer and developer of WebLabDeusto. (e-mail: iangulo@eside.deusto.es).

P. Orduña, is a Computer Engineer by the University of Deusto, Bilbao 2007. Nowadays he is a Research Assistant at the Ambient Intelligence department of DeustoTech - Tecnológico Fundación Deusto, and a PhD student at the University of Deusto, and his research is focused on Remote Laboratories. He is the lead software designer and developer of WebLab-Deusto. (e-mail: pablo@ordunya.com).

J. Irurzun is a last year student of Computer Engineering in the Faculty of Engineering of the University of Deusto. He has been with the WebLab- Deusto research group since 2007. (e-mail: irurzun@deusto.es).

This article was modified from a presentation at the REV2010 Conference at KTH, Stockholm, Sweden in June 2010. Submitted July 15th, 2010. Published as resubmitted by the authors July 29th, 2010. 